\title{
MAINE COAST WINDS
}

Quarterly Technical Progress Report for the period April - June 2000

PREPARED FOR THE UNITED STATES DEPARTMENT OF ENERGY Under Cooperative Agreement No. DE-FC36-99G010462, A000

Date Published - July 2000

\author{
Harley C. Lee \\ and Michael Boice \\ Endless Energy Corporation \\ New Gloucester, Maine
}




\section{DISCLAIMER}

This report was prepared as an account of work sponsored by an agency of the United States Government. Neither the United States Government nor any agency thereof, nor any of their employees, make any warranty, express or implied, or assumes any legal liability or responsibility for the accuracy, completeness, or usefulness of any information, apparatus, product, or process disclosed, or represents that its use would not infringe privately owned rights. Reference herein to any specific commercial product, process, or service by trade name, trademark, manufacturer, or otherwise does not necessarily constitute or imply its endorsement, recommendation, or favoring by the United States Government or any agency thereof. The views and opinions of authors expressed herein do not necessarily state or reflect those of the United States Government or any agency thereof. 


\section{DISCLAIMER}

Portions of this document may be illegible in electronic image products. Images are produced from the best available original document. 


\section{Summary}

The Maine Coast Wind Project is intended to verify the performance of the AOC $15 / 50$ turbine under coastal conditions. A secondary goal is to create a model for commercially competitive wind power installations at small, distributed sites. Endless Energy Corporation ("EEC") has made considerable progress in the first installation, and is currently in discussion with a party for the second turbine.

\section{Site 1: G.M. Allen \& Sons' blueberry processing plant, Orland Maine}

The 100' Rohn tower was received on-site in mid-May, and is scheduled to be assembled in July. A variety of delays from the turbine manufacturer have pushed the estimated date for the complete installation to mid-August. The foundation was poured and anchor bolts placed in late June, along with burial of the conduit run from the foundation to the building in which all turbine controls will be located. A site diagram is included as Exhibit A.

EEC was pleased with the response to our request for bids for both foundation and crane work. A bid has been accepted for crane operations, and the contract is in the final draft stage. A windsmith has been tentatively identified. He appears to be a well-qualified individual who also happens to live off-grid with a vintage 3-kW Jacobs wind generator he restored himself.

The control boxes will be shipped the first week of July. Payment has been made for the blades, and they should ship in July as well. The latest word from the turbine manufacturer puts their receipt of the generator at July $28^{\text {th }}$, but the: arrival date for the casting is still unknown. Once all parts are received by AOC, they estimate 10 working days in-house for assembly and painting. Mid-August is the current estimate for delivery to EEC, and final site work.

While f.ugust is still a low-wind month, the Allen's plant manager is anxious to see the turbine installed and have it begin supplying electricity. August and September are the two biggest months of electrical usage at the plant. The standard net billing contract from the regional utility, Central Maine Power ("CMP") is acceptable to the plant manager, and he expects to sign it soon.

CMP has informed EEC and $A O C$ that the currently planned protective relaying does not meet their standards. The full discussion via email is included as Exhibit $B$; the initial message stated:

CMP requires UTILITY GRADE relaying for over/under voltage and for over/under frequency as specified on page 21 of the CMP "Interconnection Requirements for Generation." 
The page referred to in the CMP manual is included as Exhibit $C$. EEC will soon begin discussions with CMP and AOC to reach an amicable, safe and costeffective solution.

\section{Additional Sites}

The previous quarterly report described discussions with the power district on Monhegan Island. While the power district and several residents are in favór of pursuing the installation of a wind turbine, island politics tend to run on a slow scale; i.e. "island time" is not "mainland time." EEC has estimated it could take up to a year before a turbine could be installed on Monhegan Island, and consequently has relegated the site to a standby status.

The Deer Isle, Maine, school district is still highly interested in having a wind turbine at its new elementary school. Favorable discussions have been taking place with the school superintendent. EEC has obtained summarized electrical consumption data for the district's schools for January - December 1999. The current island schools paid an average rate of 17. cents per kwh last year; including generating, transmission and distribution fees (different schools pay somewhat different rates, as the district includes buildings both on the mainland and on the island; the new school will be on the island).

While wind speeds at the site appear to be only moderate $(11-12.5 \mathrm{mph}$ estimated), the current high retail electrical rates make a turbine installation much more feasible. In addition, school board members, science and industrial arts teachers have expressed high levels of interest in including wind energy in the school curriculum at all grade levels.

A presentation before the school board is scheduled for July $19^{\text {th }}$. A map of the general area is included as Exhibit $D$. Exhibit $E$ is a larger scale map showing the relationship of the Allen \& school sites.

Michael Boice

Project Development Associate 
Exhibit A

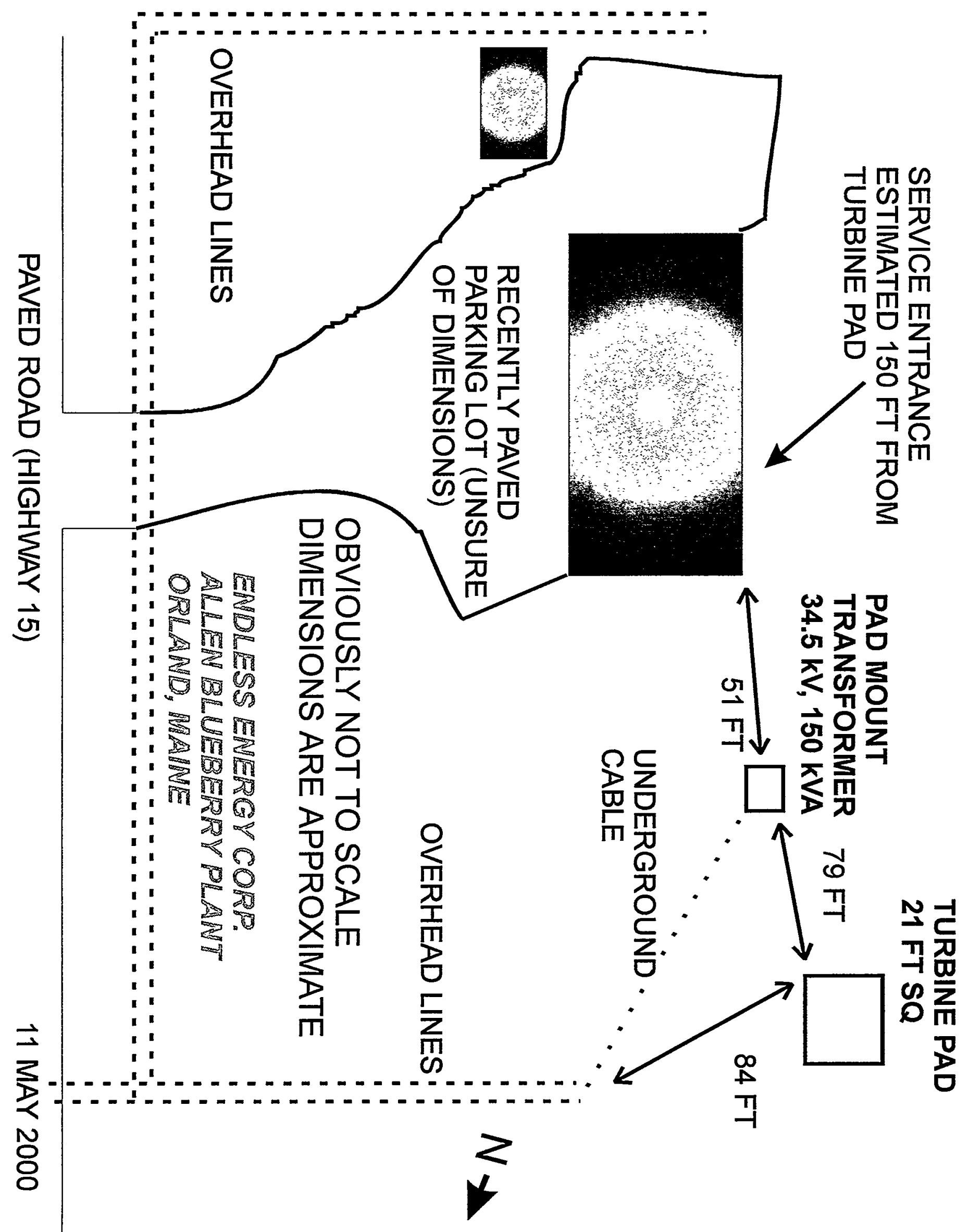




\section{Exhibit B}

Date: Thu, 15 Jun 2000 08:27:47 -0400

From: "Paul D. Anderson" <paul.anderson@cmpco.com>i

Organization: Central Maine Power Company

To: schilds <schilds@vermontel.net>

CC: Mike Boice <mike@endlessenergy.com>,

"Mary A. Smith" <mary.A.smith@cmpco.com>

Subject: Re: Wind Turbine at Orland

I am bound by CMP's document "Interconnection Requirements for Generation".

The

only deviation from "Utility Grade" relaying allowed by this document is for

single phase systems $25 \mathrm{KW}$ or smaller.

In support of our requirement in this particular case: This facility has a

fairly large synchronous motor. This motor combined with your power factor

compensation could provide the excitation required to keep this generator on

line after a loss of CMP power. Regrettably there are only two alternatives I'm ..... aware of to using utility grade relaying: 1. perform an extensive analysis of each situation as it comes about. This is a problem on distribution circuits as situations change quite often on these circuits so justifying the cost of the analysis is questionable at best. 2. allow generation to come on based on some. other criteria than our "Interconnection Requirements for Generation". This isn't likely.

At some future date the "Interconnection Requirements for Generation" may be. . changed to allow some size 3 phase machine, supplied as a system, to come on line within CMP's service area. We are not there today so I'm bound by the current document.

schilds wrote:

$>$ Good Afternoon Mike and Paul:

$>$

$>$ Paul thank you for the information about the relays.

$>$

$>$ The quotes that I have received from Basler for your recommended relays are

$>\$ 1025$ for the BE1-27/29 and $\$ 1980$ for the 81 O/U. With two 27/29 and 1

$>81 / \mathrm{OU}$ the added cost would be over $\$ 4000$ not including 2 additional PTs and

$>$ any boxes/mounting. These relays are not part of our standard turbine

$>$ controller. In fact we would recomend against the additional expense as

$>$ unnecessary for the safe operation of the turbine. We have installed

$>$ turbines at many different locations both utility and industrial/cu: "morcial

$>$ sites for 7 years and have never been required to install utility $g$;

> meters at any other site. The other site in Maine (connected to Me, ' . Slic

$>$ Service) has our standard controller and grid protection. 
$>>$--.-Original Message----

> > From: Paul D. Anderson [mailto:paul.anderson@cmpco.com]

> > Sent: Wednesday, June 07, 2000 9:26 AM

$>>$ To: Susan Childs

$>>$ Cc: Mary A. Smith

$>>$ Subject: Re: Wind Turbine at Orland

$>>$

$>>$

$>>$ Today many of the multifunction processor based relays are

$>>$ expensive and would

$>>$ be overkill for your application. Beckwith Electric ues to make a

$>>$ relay called

$>>$ a pride which would do just what you need. Others may also. You

$>>$ can also use

$>>$ Basler Electric's BE1 series however you would need 3 relays

$>>$ here. Two each

$>>27 / 59$ relays and one $81 \mathrm{O} / \mathrm{U}$ relay. With Basler I would think you would use

$>>$ relays powered from $120 \mathrm{VAC}$ and with normally closed output

$>>$ contacts which

$>>$ would trip your contactor directly upon opening. You will need a couple of.

$>>$ PT's if you use Basler as they don't make a relay for 480vac

$>>$ signal input. You

$>>$ need to monitor all three phases for voltage and that is normally

$>>$ done through

$>>$ two VT's as shown on page 21 of CMP's "Interconnection Requirements for

$>>$ Generation". This allows monitoring all three phase voltages

$>>$ with two relays.

$>>$

$>>$ The model's from Basler I would use are:

$>>$ BE1-27/59 Style A3H-E1J-AONOF

$>>$ and BE1-81O/U Style T3G-E1J-A7NOF

$>>$

$>>$ Any questions let me know.

$>>$

$>>$ Susan Childs wrote:

$>>$

$>>$ Paul:

$>>>$

$>>>$ Your recommendations on suggested manufacturers or model \#'s.

$>>>$

$>>>$ Sue Childs

$>>>$

$>>>$----Original Message----- 
$>>>$ From: Paul D. Anderson [mailto:paul.anderson@cmpco.com]

$>>>$ Sent: Friday, June 02, 2000 11:28 AM

$>>>>$ To: Mike Boice; Sue Childs; Hariph M. Smith; Ronald E. Grant; Paul D.

$>>>$ Anderson

$>>>>$ Subject: Wind Turbine at Orland

$>>>>$

$>>>>$

$>>>>\mathrm{CMP}$ has reviewed the specification of the $66 \mathrm{KW}$ wind turbine and its

$>>>>$ over/under voltage monitor module.

$>>>>$

$\therefore$ ?

$>>>>$ CMP requires UTILITY GRADE relaying for over/under voltage and for

$>>>>$ over/under frequency as specified on page 21 of the CMP

$>>$ "Interconnection

$>>>>$ Requirements for Generation". This relaying needs to incorporate a

$>>>>$ testing means in its installation configuration such that relay set

$>>>>$ points can be confirmed without interfering with wiring. This is

$>>>>$ typically accomplished by installing test blocks which are used to

$>>>>$ switch the relay out of service while providing points to inject

$>>>>$ voltages and monitor the relays output contacts. A utility grade relay

$>>>>$ is one which meets additional testing criteria above that

$>>$ require by $\mathrm{UL}$

$>>>>$ and CSC as specified in ANSI/IEEE C37.95 Guide for Protective

Relaying

$>>>>$ of Utility-Consumer Interconnections.

$>>>>$.

$>>>>$ There are multifunction relays available which could possibly be

$>>>>$ included to control your generator contactor directly.

$>>>$

$>>>$ If I can be of further assistance do not hesitate to contact me. 
2. Type II Installations - (Figure III-3.)

These are three-phase generators (induction or synchronous ) or static power converters with a maximum generation of $100^{\prime} \mathrm{kW}$ connected to a distribution circuit, usually $12 \mathrm{kV}$ (7200 V phase to neutral). This installation provides for power flow from the Generator's facility to the T\&D system. However, the primary reason for the generation may be to supply the Generator's own load.

- This installation requires a primary circuit breaker, circuit switcher, recloser, or contactor designated as component "52G" in Figure III-3.

- If fused on the high-side, the fuse size will be specified by CMP, based on the generator output, the Generator facility's load, and the available fault current at the generator's location.

- The Generator's control scheme for breaker "52M" must be designed to allow for its closing only if the feed from CMP is energized, and breaker "52G" is open. If breaker " $52 \mathrm{M}$ " is open and breaker " $52 \mathrm{G}$ " is closed, the Generator may synchronize across breaker "52M." If the feed from CMP is not energized, then the Generator's control scheme must prevent closing. of breaker "52M." If "52M" is a fuse, the Generator's control scheme must prevent closing of "52G" if the feed from CMP is not energized.

- VTs providing sensing input to Intertie Protective Relays must be .continuously rated for line-to-line voltage. 


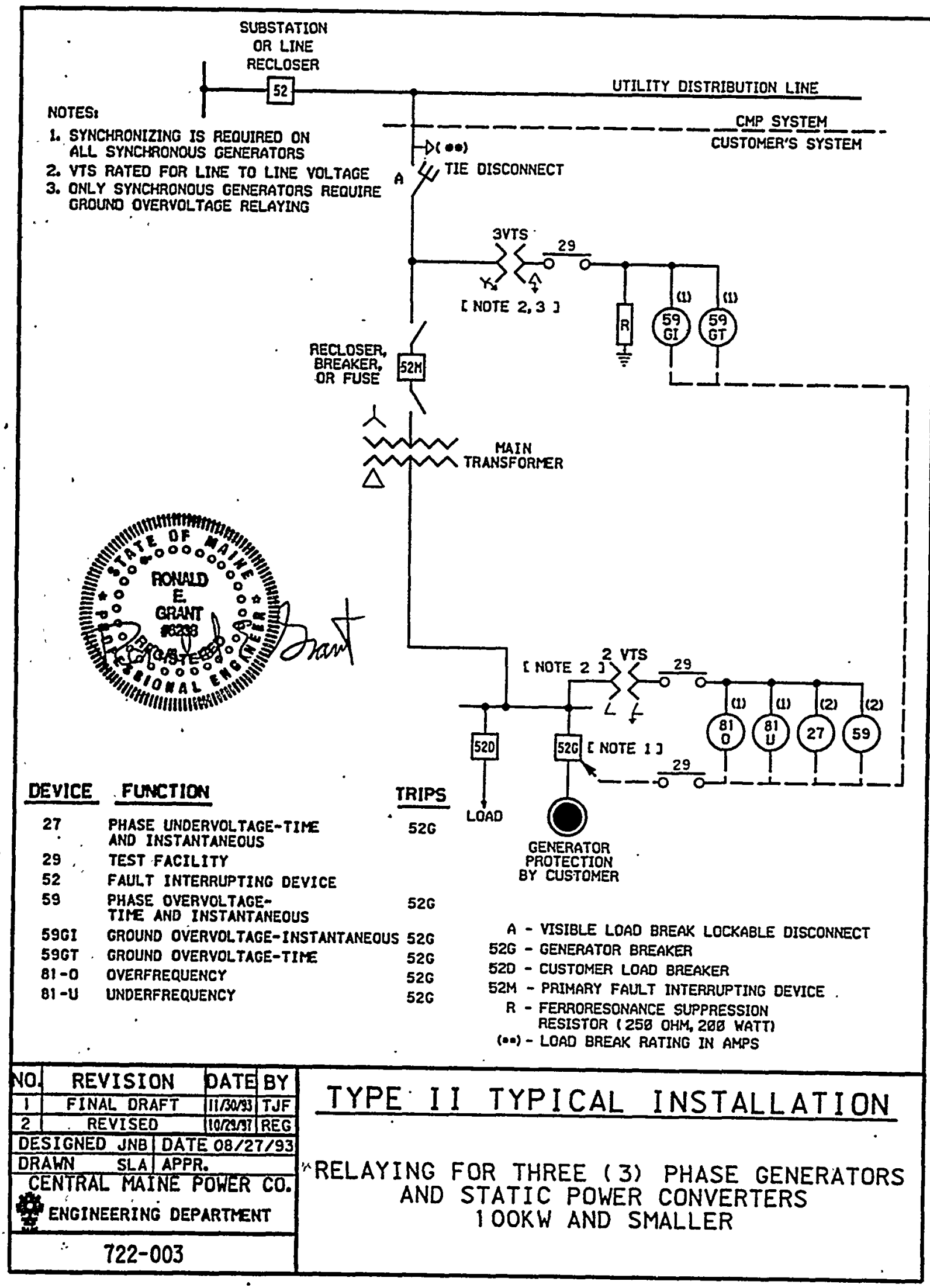

Figure III-3: Type II Typical Installation. 


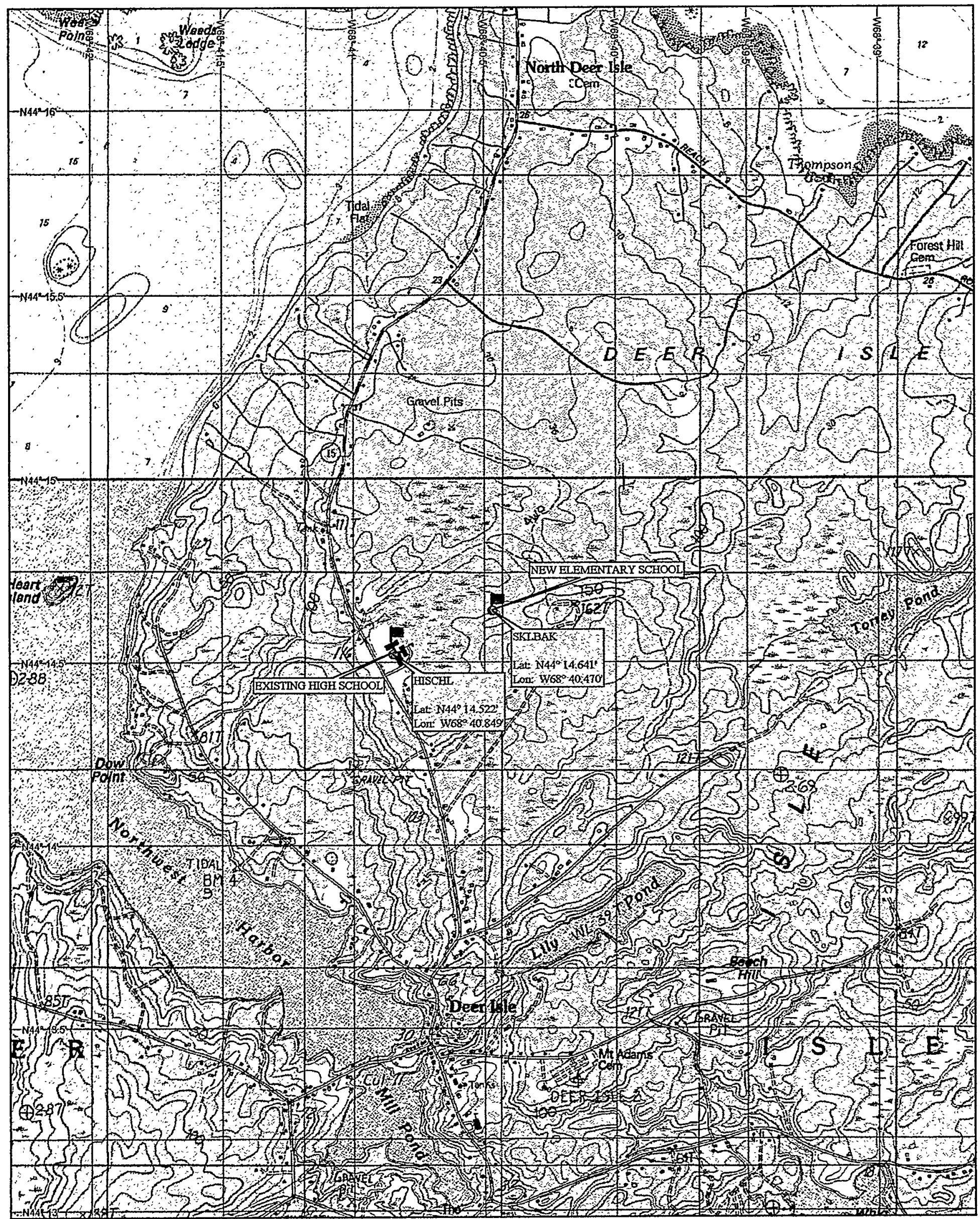

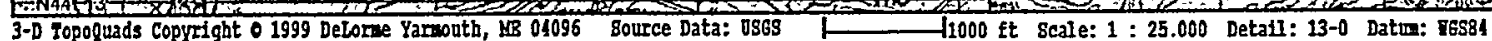




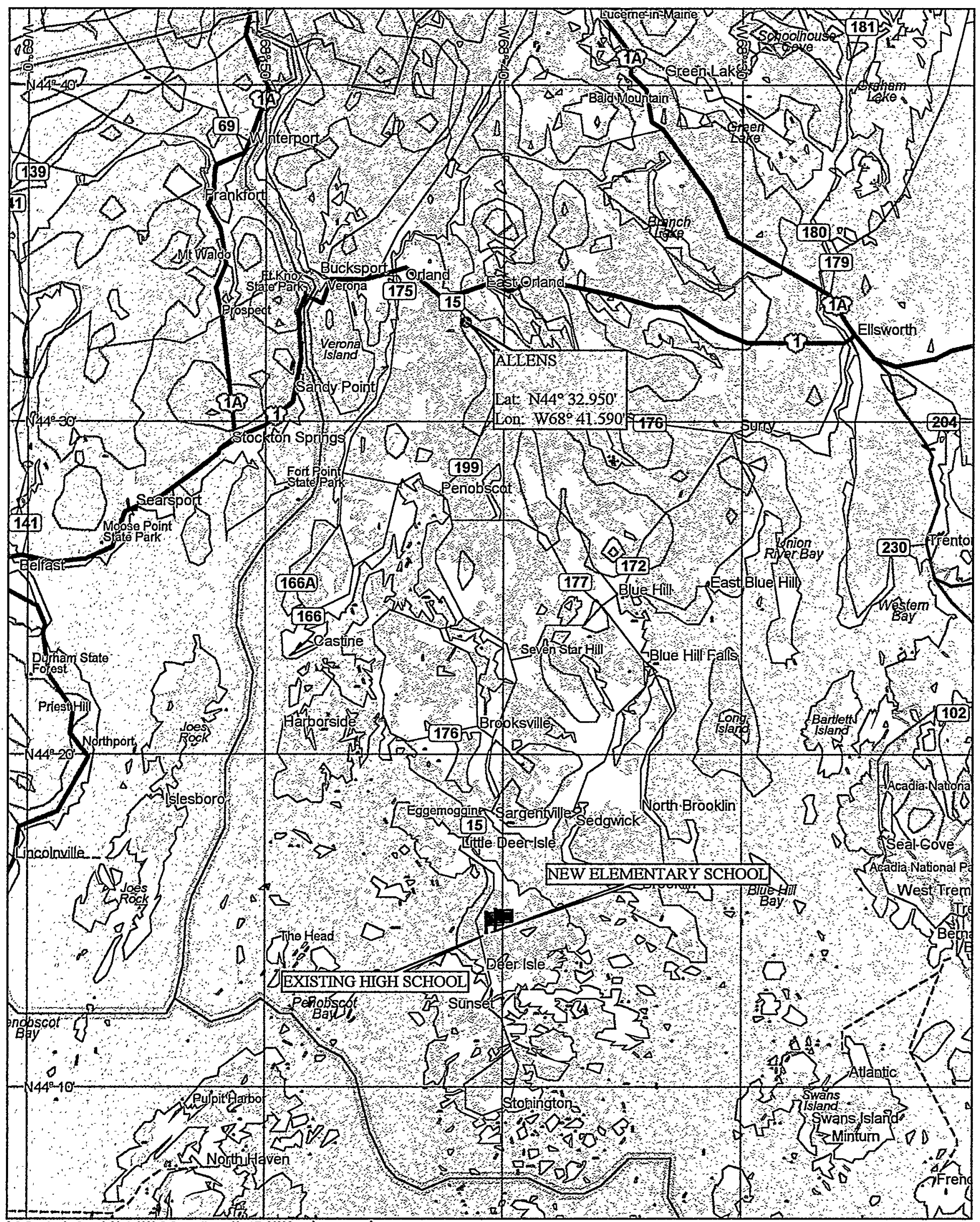

